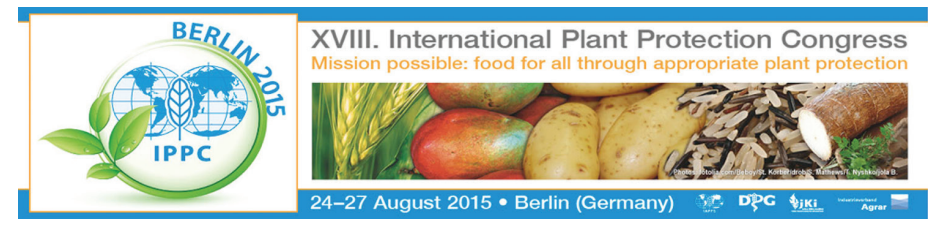

CONGRESS REPORT

\title{
Highlights at the 18th International Plant Protection Congress (IPPC) in Berlin "Mission possible: Food for all through appropriate plant protection"
}

Berlin, IPPC2015, the 18th International Plant Protection Congress - under the patronage of the International Association for the Plant Protection Sciences (IAPPS), the German Scientific Society for Plant Protection and Plant Health (DPG), the Julius Kühn-Institut (JKI) and the Agriculture Industry Association (IVA) - was taking place at the Henry Ford Building in Berlin from August 24 to 27, 2015. Bringing together plant protection specialists from all continents and providing the opportunity to exchange their knowledge and experiences, the congress was a great success: More than 1200 delegates from over 95 countries were participating at the most important platform for exchanging the latest research results and innovations of plant protection, inspired by new ideas, professional contacts and a warm and welcoming atmosphere. "The international meeting helped to address open questions on agricultural, biological and technical matters that allow us to provide proper solutions on time despite the continuously rising demand on food in the future", said Holger B. Deising, Chair of the IPPC Programme Committee, University Halle-Wittenberg (Halle/ Saale, Germany).

"Mission possible: food for all through appropriate plant protection" was the headline of the IPPC Congress 2015. The 360 oral contributions and the more than 800 posters that have been presented were promising: Expecting a global population of 9 billion people by the year 2050, the United Nations can be sure that food security for the growing population can be achieved - one of the biggest global challenges of the 21 st century. In spite of limited or even fewer resources, using less water, fertilizers and energy in a changing climate, the approach demonstrated by the delegates bases on a sustainable intensification of crop production but of mutual collaboration of all parties of plant production, farmers, extension services, research and education, including scientific civil societies, regulators and administrations, storage and trade companies, retailers, and consumers. 
"The whole product chain from farm to fork on the basis of a harmonized legal framework has to be developed as the key factor in favor of those who cannot help themselves", emphpasised Falko Feldmann, Deutsche Phytomedizinische Gesellschaft e.V. (Braunschweig, Germany), managing director IPPC2015. "Delegates underlined that a generally accepted agro-ethical code of practice should be recognized by interacting countries. Without political stability the best agricultural system may fail."

Renowned experts from discussed the implementation of international standards for integrated plant protection, also including organic farming. One of the basic ideas was the necessity of professional plant protection especially in countries with food shortage where often more than one third of all cultivated plants get lost because they are exposed to diseases, pests and weeds, or suffer from harmful environmental influences. International renowned keynote speakers were Per Pinstrup-Andersen, Cornell University (Ithaca, NY/United States) and Myron Zalucki, University of Queensland (Brisbane, Australia). Patrick Schweizer, Leibniz Institute of Plant Genetics and Crop Plant Research (Gatersleben, Germany) presented the actual research of Genetics and Genomics: "Planting future - plants resistant to biotic and abiotic stresses".

Regarding to the mission all delegates agreed that integrated pest management plays a key role, so that an integrated approach to plant protection provides the best means of achieving effective and resilient plant protection strategies. Knowledge-based and using scientific understanding of pest population dynamics and the role of natural control mechanisms management practices could be combined in a sustainable manner. Robust varieties, crop rotation, balanced fertilization and good soil management were seen as important elements. Only as a last resort integrated pest management should include the use of synthetic plant protection products.

A huge number of alternatives to chemical control means, including botanicals, plant strengtheners or beneficial organisms like hyperparasitic insects or nematodes were discussed, their limitations highlighted and their integration to IPM strategies demonstrated. A forthcoming break through research area was identified in the microbiom sessions and the workshops concerned with endophytes and useful rhizosphere microorganisms for use in agriculture. "It was encouraging to see that all over the planet healthy plants are estimated a prerequisite for overcoming hunger and feeding the world today and tomorrow", highlighted Falko Feldmann. "Production of healthy plants requires good
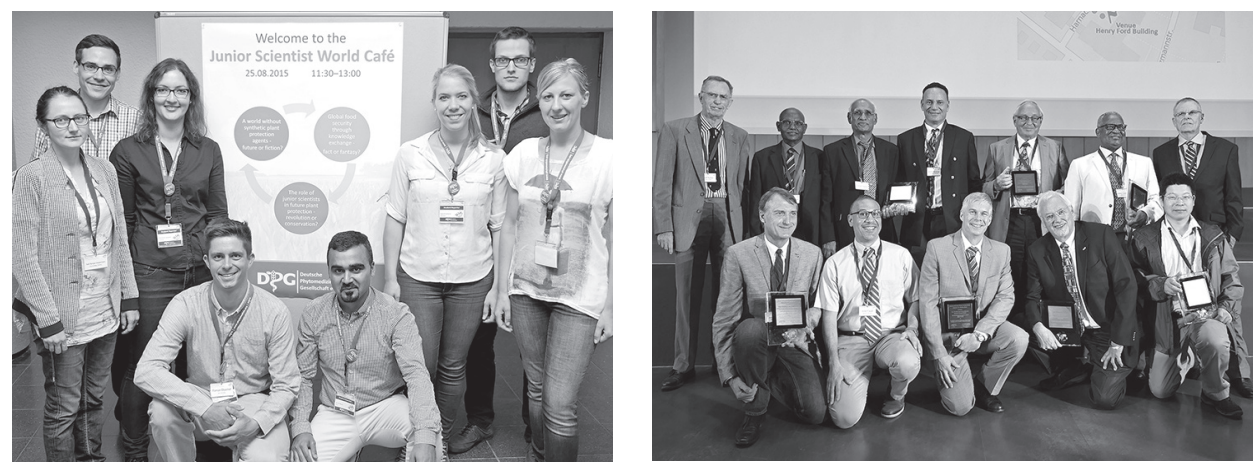
practice in agriculture, in particular in plant breeding, plant protection and crop management. Bearing in mind the whole food chain, there is also a need to minimize food losses and food waste."

In spite of the pests and diseases which would gain even more importance due to global warming, as well as invasive species, the delegates were sure, all problems could be overcome if knowledge and expertise would be shared to advance science, and to network with colleagues around the world like it has been realized during the IPPC 2015.
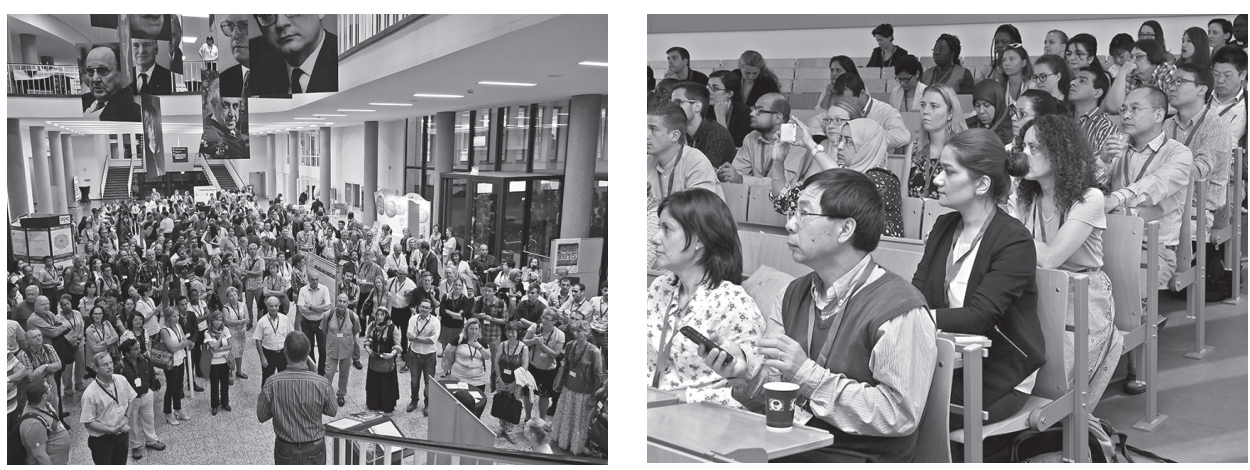

Importance of networking had been pointed out by the young scientist's world café, the student reporters, the scientific societies meetings and lectures concerned with the integration of education. These excellent actions showed that scientific civil societies could be a decisive nucleus for the interaction of research, extension service, administration and industry. In conclusion, it can be said that the IPPC2015 was an important step for the successful actual work as well as in future times.

All can be found at www.ippc2015.de. The next IPPC will take place in Hyderabad, India in 2019. 